\title{
Recovery of Valuable Metals from Spent Lithium Ion Batteries (LIBs) Using Physical Pretreatment and a Hydrometallurgy Process
}

\author{
Kai-Lun Chiu ${ }^{*}$, Yun-Hwei Shen, Yi-Hsuan Chen, Kaun-Yu Shih \\ Department of Resources Engineering, National Cheng Kung University, Tainan City, Taiwan
}

Email address:

n48041149@mail.ncku.edu.tw (Kai-Lun Chiu)

${ }^{*}$ Corresponding author

\section{To cite this article:}

Kai-Lun Chiu, Yun-Hwei Shen, Yi-Hsuan Chen, Kaun-Yu Shih. Recovery of Valuable Metals from Spent Lithium Ion Batteries (LIBs) Using Physical Pretreatment and a Hydrometallurgy Process. Advances in Materials. Vol. 8, No. 1, 2019, pp. 12-20. doi: 10.11648/j.am.20190801.12

Received: December 28, 2018; Accepted: January 20, 2019; Published: February 21, 2019

\begin{abstract}
Lithium ion batteries are the most commonly used batteries at present, and because of the large number of people using and manufacturing them, the serious environmental problems caused by the final disposal of waste lithium batteries are worth discussing. In this study, lithium ion batteries were crushed with a crusher, and the obtained powder was then sieved and collected. The valuable metals in the lithium ion batteries were recovered using a hydrometallurgy process. The research included the use of acid leaching and chemical precipitation. Acid leaching of the cathode electrode powder with three kinds of acids, including citric acid, sulfuric acid, and hydrochloric acid, resulted in a leaching solution rich in lithium, cobalt, nickel, and manganese. The leaching solution obtained from hydrochloric acid leaching was selected as the liquid to be used for the precipitation experiments. Precipitation was performed first using a selective chemical precipitation method, and manganese was first precipitated as a black powder. The color of the leaching solution after manganese precipitation changed to dark pink, and the liquid was full of cobalt and nickel. Then, the cobalt and nickel were co-precipitated with ammonium citric, and the obtained precipitates were either pale pink or grayish pink. After precipitation of cobalt and nickel, only lithium was left in the transparent, colorless leaching liquid. Finally, lithium was concentrated through reduced pressure evaporation, and a green lithium salt was obtained.
\end{abstract}

Keywords: Spent Lithium-ion Battery, Lithium, Cobalt, Nickel, Manganese, Hydrometallurgy

\section{Introduction}

In recent years, lithium-ion batteries (LIBs) have been widely used as electro-chemical power sources for portable electronic devices such as those used in computer engineering (CE) and electric vehicles (EV). With increasing global use of such batteries for transportable applications, the need for lithium ion batteries will increase due to the corresponding global demand. This has led to growing concerns worldwide about the disposal of these batteries and the potentially harmful impact they may have on the environment.

In this study, the hydrometallurgical recovery process for lithium batteries requires pretreatment. After the battery is crushed, ground, and sieved, the preliminary plastic, iron, aluminum, and copper are separated, and NMP is used to remove the residual powder on an aluminum sheet. The positive electrode material powder is dried and then acid-impregnated to dissolve the valuable metals in the solution. Finally, the product is obtained using chemical precipitation, electrolysis, and solvent extraction.

Lithium-ion battery impregnation is mainly based on acid impregnation. The acids include nitric acid, hydrochloric acid, sulfuric acid, etc., and hydrogen peroxide is added as an oxidant. The purpose is to reduce trivalent cobalt and manganese into divalent cobalt and manganese. Bivalent cobalt and manganese are more easily impregnated and thus help improve impregnation efficiency. For example, Liang Chen [4] used sulfuric acid to obtain a cobalt impregnation rate of $95 \%$ under $4 \mathrm{M}$ and $10 \%$ hydrogen peroxide. At the same time, the use of organic acids such as sulfuric acid, hydrochloric acid, and nitric acid produces toxic gases such 
as sulfur and chlorine. Therefore, some people choose to use organic acids such as citric acid, oxalic acid, etc. Organic acids do not produce toxic gases, and the impregnation efficiency is high, but the cost is also high.

The chemical precipitation process can be divided into four parts. Because of the types of lithium ion batteries, there may be different ions in the immersion liquid. In summary, the main elements in all lithium-ion batteries are lithium, cobalt, nickel, and manganese, so the precipitation can contain these four elements. Jeong-Soo Sohn et al. [5] obtained a precipitation efficiency of $96.1 \%$ when the molar ratio of ammonium oxalate to cobalt ion was 4 , but at the same time, $90 \%$ of the nickel and copper were also co-precipitated together. ZHU Shu-guang et al. [6] used ammonium oxalate as a precipitant to react for one hour when the molar ratio of ammonium oxalate to cobalt ion was 1.2 , and at $\mathrm{pH} 2,94.7 \%$ of the cobalt was precipitated into pink cobalt oxalate. Then, lithium was precipitated using sodium carbonate.

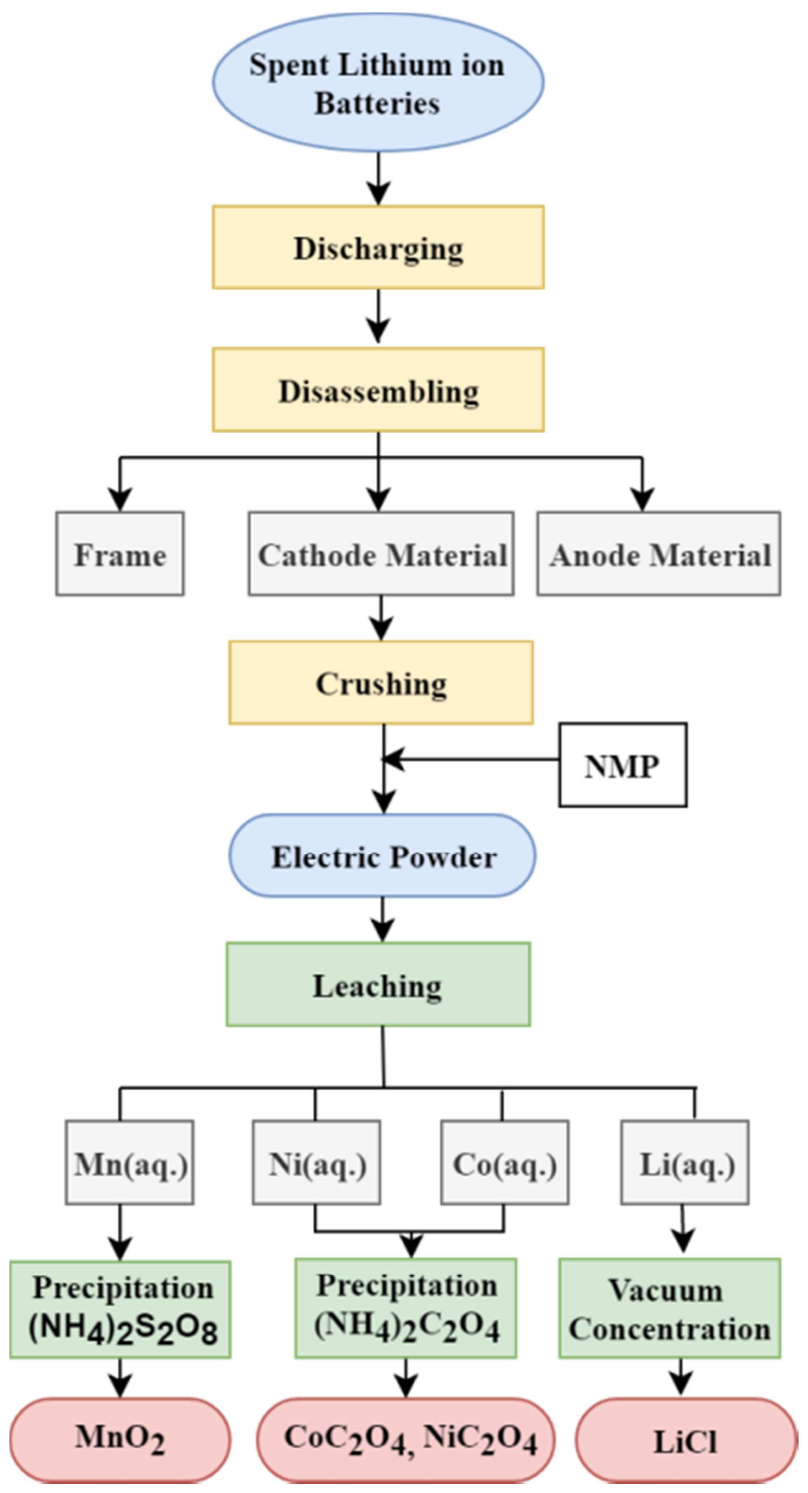

Figure 1. Experimental Process.

\section{Experimental Details}

\subsection{Experimental Process}

Spent LIBs used in the mobile phones of different manufactures were used in this study. To ensure the safety of the experiment, the samples were fully discharged at least 24 hours with $10 \%$ mass fraction $\mathrm{NaCl}$ solution and then air dried naturally before crushing. The anode and cathode powders were then separated and used for further experiments. A hydrometallurgy route was employed to recover the valuable metals in the anode and cathode powders. Different types of acid were tested for the purpose of leaching the powder. After leaching, the liquid was subjected to chemical precipitation to separate the valuable metals. The experimental process is shown in Figure 1.

\subsection{Physical Pretreatment}

Lithium-ion batteries can be divided into two discharge and disassembly steps in the pretreatment process [7], but in the disassembly process, it is easy for the positive and negative electrodes to come into contact. Once the positive and negative electrodes are in contact with each other, this often causes a short circuit, which produces self-ignition [8]. When many lithium-ion batteries are simultaneously self-igniting, a fire or even an explosion may result. Therefore, lithium batteries are usually immersed in salt water to discharge before disassembly. There are two benefits to using brine for this purpose [9]. The first reason is that brine has good electrical conductivity and can release any residual electrical energy contained in lithium-ion batteries. The high-energy heat generated by the short circuit can be absorbed by the brine without causing danger, and the brine can be reused without any further pollution. The second reason is that the price is low, and the process is efficient.

The next step is disassembling [10]. In this experiment, aluminum soft-packed lithium-ion batteries were used. The positive and negative electrodes were separated by manual splitting, and the aluminum outer packaging was also separated and then crushed separately with a crusher. The crushed cathode material contains aluminum foil and target valuable metal powders, but most of the valuable metal powder remains attached to the aluminum sheet. Therefore, it is necessary to utilize N-Methyl pyrrolidone (NMP), a polar organic solvent, to effectively separate positive electrode materials from the aluminum sheet.

In general, LIBs are made of polyvinylidene fluoride (PVDF) as an adhesive for the positive electrode material, which is also a polar organic solvent. According to the Like Dissolves Like Theory [11, 12, 13, 14], polar solutions dissolve polar substances, and non-polar solutions dissolve non-polar substances. Therefore, NMP can be used to effectively separate the positive electrode powder from the aluminum substrate. The liquid in which the NMP and the positive electrode powder is mixed is placed in an oven, and the positive electrode material powder can be obtained by removing the NMP. After obtaining the positive electrode 
material powder, the acid immersion step can be performed.

\subsection{Acid Impregnation}

\subsubsection{Impregnation Parameters}

The immersion test can be further divided into a direct acid immersion and a reducing acid immersion. A direct acid immersion is directly performed using the immersion liquid, where the reducing acid immersion is added with a reducing agent in the immersion liquid. Common inorganic acids are hydrochloric acid, sulfuric acid, nitric acid, etc. Common organic acids are: citric acid [15], DL-malic acid, oxalic acid, etc. The experimental impregnation involves the use of two inorganic acids $\mathrm{HCl}$ [16-20], $\mathrm{H}_{2} \mathrm{SO}_{4}$ [21-26], and one organic acid, of which citric acid as the main research impregnation type.
In this study, the experiments were carried out on the same powder to investigate the factors related to each acid, such as the solid-liquid impregnation ratio, the acid impregnation concentration, the temperature, and the amount of hydrogen peroxide added [12, 13, 14, 19, 27, 28]. Hydrogen peroxide was used to convert cobalt and manganese from trivalent to divalent, which made it easier to impregnate with acid. If hydrogen peroxide is not added, the leaching efficiency of cobalt and manganese will be only $60 \%$. The impregnation efficiency was investigated using different parameters, such as the solid-liquid ratio, the immersion concentration, reaction time, the amount of hydrogen peroxide added, and the reaction temperature. The experimental parameters are shown in Table 1 .

Table 1. Experimental parameters of the acid impregnation study.

\begin{tabular}{ll}
\hline Impregnation Parameter & Parameter Setting \\
\hline Concentration $(\mathrm{mol} / \mathrm{L})$ & $0.2,0.5,1,2,3,4,5$ \\
Solid-Liquid Ratio $(\mathrm{g} / \mathrm{L})$ & $20,40,60,80$ \\
Reaction Time $(\mathrm{min})$ & $5,15,30,60,90,120,150$ \\
Reaction Temperature $\left({ }^{\circ} \mathrm{C}\right)$ & $25,40,60,80$ \\
Reducing agent dose $(\operatorname{vol} \%)$ & $0,5,10,15,20$ \\
\hline
\end{tabular}

\subsubsection{Reaction Equations}

Compared with inorganic acids, avoiding secondary pollution emission into the environment is easier with the use of organic acids, and they are easier to degrade and recycle. Moreover, inorganic acids are prone to causing gaseous

pollution such as $\mathrm{Cl}_{2}, \mathrm{SO}_{3}$, and $\mathrm{NOx}$, and are also likely to cause harm to both humans and the environment. The reaction equation for citric acid is shown in equations (1) and (2).

$$
\begin{aligned}
& 6 \mathrm{H}_{3} \mathrm{Cit}_{(\mathrm{aq})}+2 \mathrm{LiCoO}_{2(\mathrm{~s})}+\mathrm{H}_{2} \mathrm{O}_{2(\mathrm{aq})}=2 \mathrm{Li}^{+}{ }_{(\mathrm{aq})}+6 \mathrm{H}_{2} \mathrm{Cit}_{(\mathrm{aq})}+2 \mathrm{Co}^{2+}{ }_{(\mathrm{aq})}+4 \mathrm{H}_{2} \mathrm{O}+\mathrm{O}_{2(\mathrm{~g})} \\
& 6 \mathrm{HCit}^{2-}{ }_{(\mathrm{aq})}+2 \mathrm{LiCoO}_{2(\mathrm{~s})}+\mathrm{H}_{2} \mathrm{O}_{2(\mathrm{aq})}=2 \mathrm{Li}^{+}{ }_{(\mathrm{aq})}+2 \mathrm{Co}^{2+}{ }_{(\mathrm{aq})}+6 \mathrm{Cit}^{3-}{ }_{(\mathrm{aq})}+4 \mathrm{H}_{2} \mathrm{O}+\mathrm{O}_{2(\mathrm{~g})}
\end{aligned}
$$

The hydrochloric acid reaction equation is as shown in equation (3):

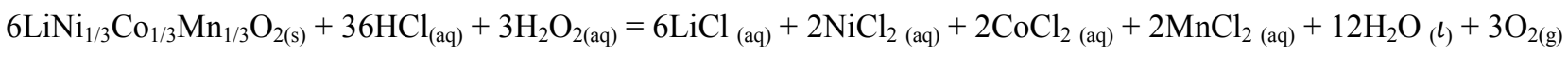

The sulfuric acid reaction equation is shown in Equation (4):

$$
6 \mathrm{LiNi}_{1 / 3} \mathrm{Co}_{1 / 3} \mathrm{Mn}_{1 / 3} \mathrm{O}_{2}(\mathrm{~s})+9 \mathrm{H}_{2} \mathrm{SO}_{4}(\mathrm{aq})+3 \mathrm{H}_{2} \mathrm{O}_{2}(\mathrm{aq})=3 \mathrm{Li}_{2} \mathrm{SO}_{4(\mathrm{aq})}+2 \mathrm{NiSO}_{4(\mathrm{aq})}+2 \mathrm{CoSO}_{4(\mathrm{aq})}+2 \mathrm{MnSO}_{4(\mathrm{aq})}+12 \mathrm{H}_{2} \mathrm{O}(\boldsymbol{l})+3 \mathrm{O}_{2(\mathrm{~g})}
$$

\subsection{Selective Chemical Precipitation Separation}

The selective chemical precipitation in this study was divided into two steps. The first step was the precipitation of manganese. The $\mathrm{pH}$ of the impregnation solution was adjusted with $1 \mathrm{M} \mathrm{NaOH}$ to $\mathrm{pH} 2$, and ammonium persulfate $\left(\left(\mathrm{NH}_{4}\right)_{2} \mathrm{~S}_{2} \mathrm{O}_{8}\right)$ is added to precipitate manganese. Then, $\mathrm{MnO}_{2}$ precipitate was obtained. The manganese precipitation reaction mechanism is shown in Equation (5).

$$
\mathrm{Mn}^{3+}{ }_{(\mathrm{aq})}+\left(\mathrm{NH}_{4}\right)_{2} \mathrm{~S}_{2} \mathrm{O}_{8(\mathrm{aq})}+2 \mathrm{H}_{2} \mathrm{O}(\mathrm{aq})=\mathrm{MnO}_{2(\mathrm{~s})}+\left(\mathrm{NH}_{4}\right)_{2} \mathrm{SO}_{4(\mathrm{aq})}+\mathrm{H}_{2} \mathrm{SO}_{4(\mathrm{aq})}+2 \mathrm{H}^{+}
$$

The $\mathrm{MnO}_{2}$ was removed through solid-liquid separation, and $\mathrm{Li}^{2+}, \mathrm{Co}^{2+}, \mathrm{Ni}^{2+}$, and trace amounts of $\mathrm{Mn}^{2+}$ were left in the remaining impregnation solution. The $\mathrm{pH}$ of the impregnation solution was adjusted with $1 \mathrm{M} \mathrm{NaOH}$ to $\mathrm{pH} 2$.
Then, cobalt oxalate and nickel oxalate were precipitated by adding oxalic acid ammonia $\left(\left(\mathrm{NH}_{4}\right)_{2} \mathrm{C}_{2} \mathrm{O}_{4}\right)$.

Cobalt precipitation reaction mechanism is shown in equations (6) and (7):

$$
\begin{aligned}
& \mathrm{CoSO}_{4}(\mathrm{aq})+\left(\mathrm{NH}_{4}\right)_{2} \mathrm{C}_{2} \mathrm{O}_{4}(\mathrm{aq})=\mathrm{CoC}_{2} \mathrm{O}_{4}(\mathrm{~s})+\left(\mathrm{NH}_{4}\right)_{2} \mathrm{SO}_{4} \\
& \mathrm{NiSO}_{4}(\mathrm{aq})+\left(\mathrm{NH}_{4}\right)_{2} \mathrm{C}_{2} \mathrm{O}_{4}(\mathrm{aq})=\mathrm{NiC}_{2} \mathrm{O}_{4}(\mathrm{~s})+\left(\mathrm{NH}_{4}\right)_{2} \mathrm{SO}_{4}
\end{aligned}
$$




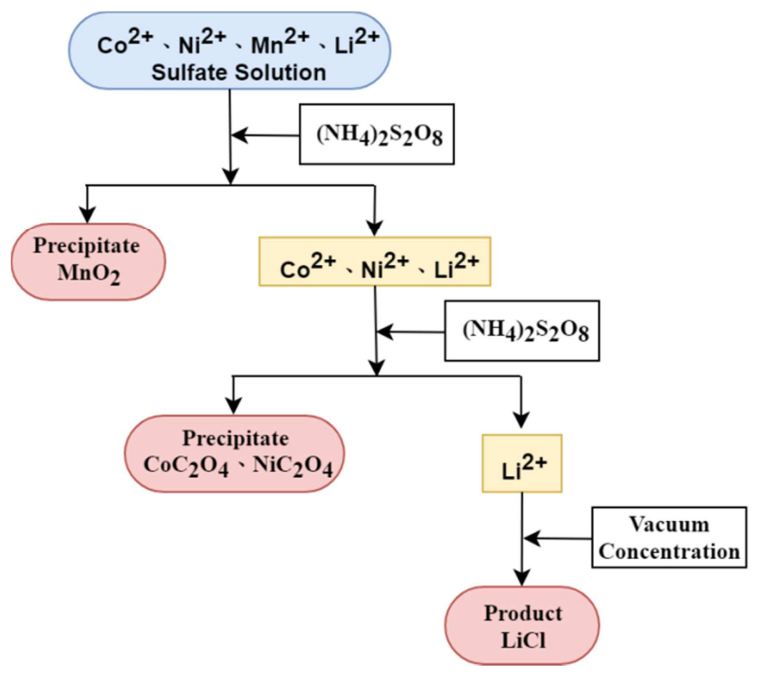

Figure 2. The selective chemical precipitation separation process.
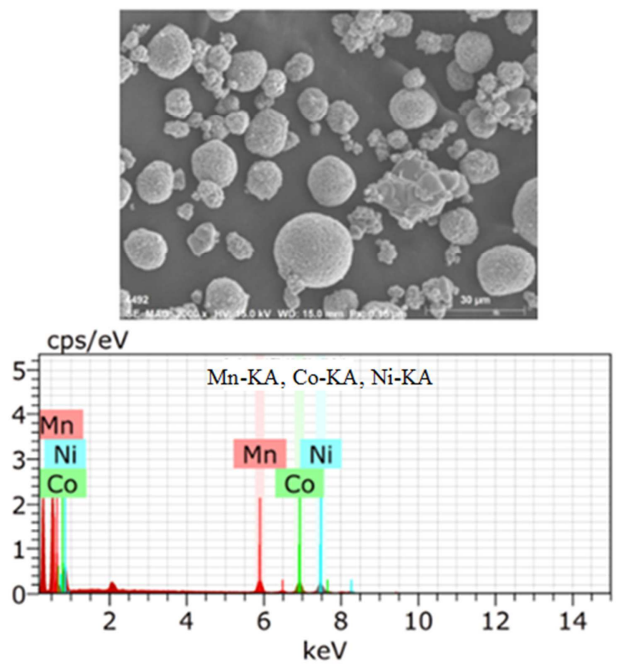

Figure 3. SEM-EDS analysis results for the positive electrode powder.

Figure 4 shows the XRD analysis results for the positive electrode powder. It can be seen from the analytical results that the positive electrode powder is a single crystal structure, mainly composed of lithium cobalt nickel manganese oxide $\left(\mathrm{LiNi}_{1 / 3} \mathrm{Co}_{1 / 3} \mathrm{Mn}_{1 / 3} \mathrm{O}_{2}\right)$.

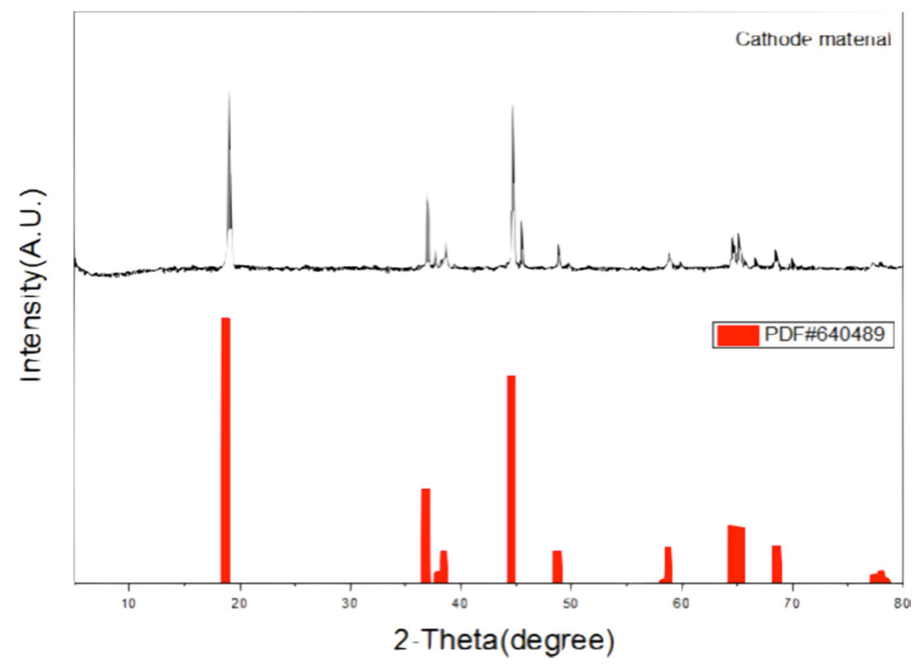

Figure 4. XRD positive powder results. 


\subsection{Physical Pretreatment}

At this stage, the lithium ion battery chips that were crushed using the crusher were placed in a sieve for screening. Figure 6 shows the weight cumulation distribution of the crushed particles, where the histogram represents the weight percentage contained on each screen surface. From the screening results, it can be inferred that most of the lithium ion battery chips crushed by the crusher were generally larger than $9.51 \mathrm{~mm}$, while the other main products were electrode powder and a small amount of finely divided plastic collected at the bottom of the sieve. Most heavy plastics could be removed through the use of heavy liquid sorting.

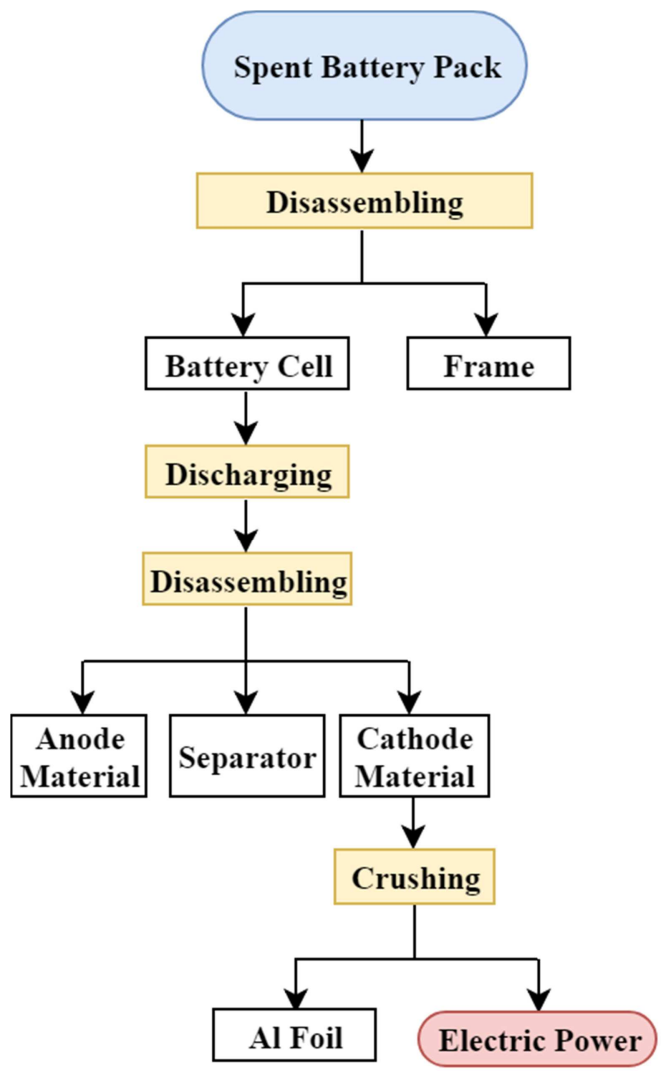

Figure 5. The physical pretreatment process.

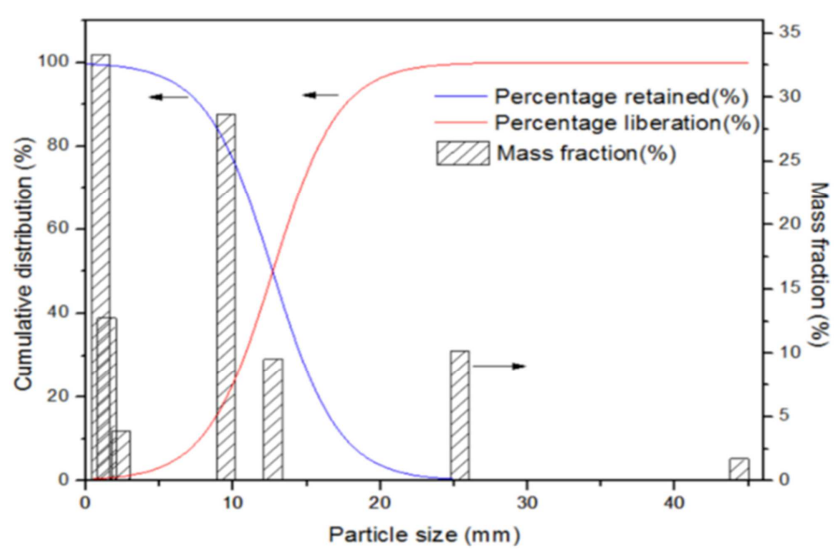

Figure 6. The weight cumulation distribution of the crushed particles.

\subsection{The Acid Impregnation Results}

\subsubsection{Sulfate Impregnation}

As shown in Figure 7, this experiment was carried out under the optimal parameters at a sulfuric acid concentration of $4 \mathrm{~N}$, a solid-liquid ratio of $40 \mathrm{~g} / \mathrm{L}$, a reaction time of 60 min, a reaction temperature of $60^{\circ} \mathrm{C}$, with hydrogen peroxide at $5 \mathrm{vol} \%$. It can be clearly seen from the figure that the leaching efficiency increased with increases in the sulfuric acid concentration.

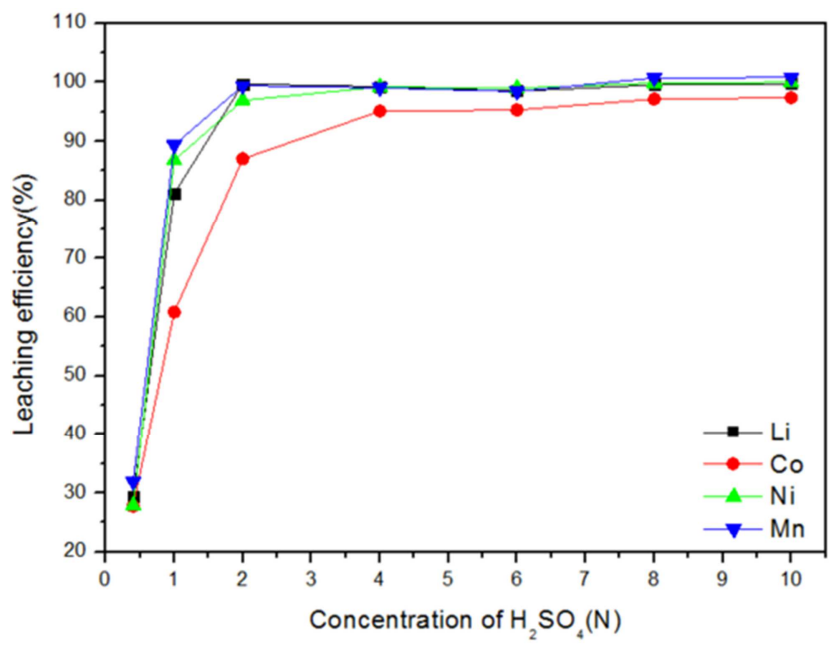

Figure 7. The effect of sulfuric acid concentration.

\subsubsection{Hydrophobic Impregnation}

Figure 8 shows that the experiment was carried out with the optimal parameters at a hydrochloric acid concentration of $4 \mathrm{~N}$, a solid-liquid ratio of $80 \mathrm{~g} / \mathrm{L}$, a reaction time of 90 minutes, a reaction temperature of $60^{\circ} \mathrm{C}$, with hydrogen peroxide at $20 \mathrm{vol} \%$. It can be clearly seen from the figure that the leaching efficiency increased with increases in the hydrochloric acid concentration.

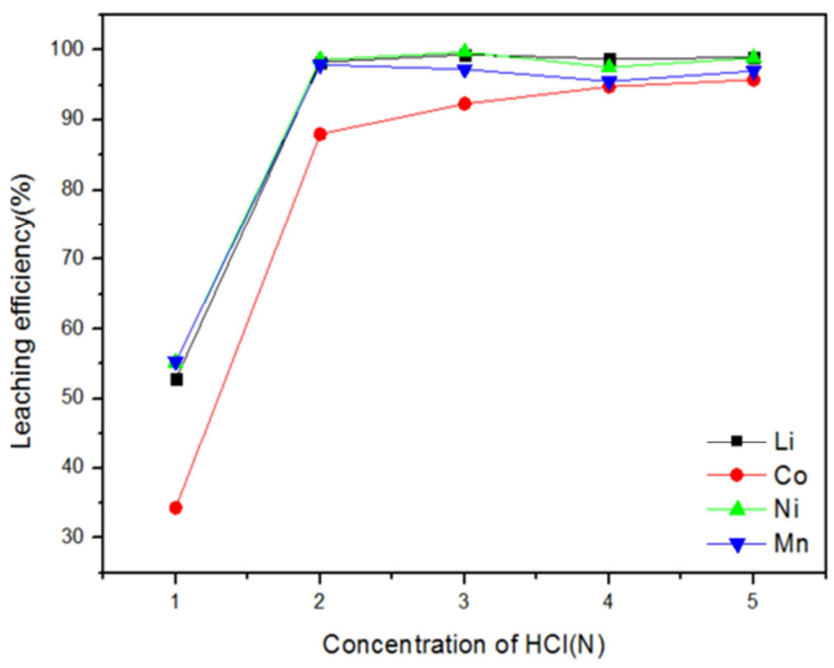

Figure 8. The effect of the hydrochloric acid concentration. 


\subsubsection{Citric Acid Impregnation}

As shown in Figure 9, this experiment was carried with the optimal parameters at a citric acid concentration of $3 \mathrm{~N}$, a solid-liquid ratio of $40 \mathrm{~g} / \mathrm{L}$, a reaction time of 120 minutes, a reaction temperature of $90^{\circ} \mathrm{C}$, with hydrogen peroxide at 20 vol\%. It can be clearly seen from the figure that the leaching efficiency increased with increases in the citric acid concentration.

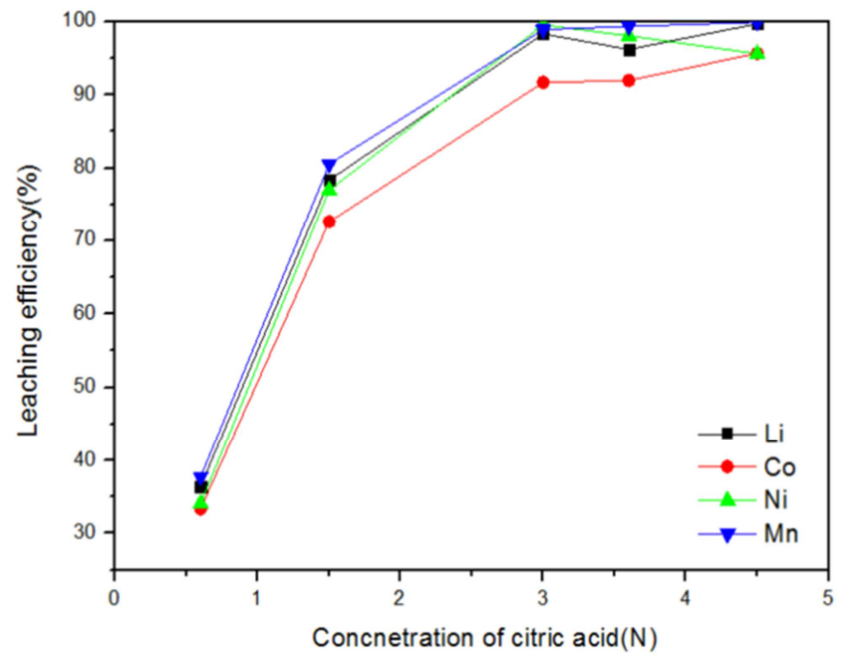

Figure 9. The effect of citric acid concentration.

\subsection{Results of Selective Chemical Precipitation Separation}

\subsubsection{Manganese Precipitation}

In the chemical precipitation experiments, manganese was

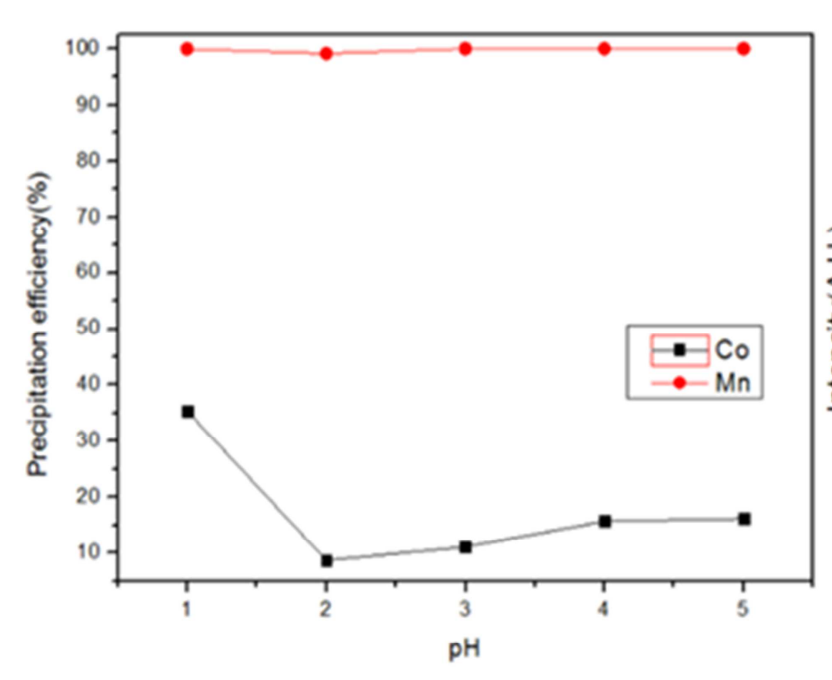

(a) precipitated first with ammonium persulfate. The results for the manganese precipitation are shown in Figure 10(a). This figure shows the effect of $\mathrm{pH}$ on the precipitation efficiency of manganese and cobalt at $80^{\circ} \mathrm{C}$ for one hour. Although increasing the $\mathrm{pH}$ contributes to the precipitation efficiency of cobalt, if the $\mathrm{pH}$ is raised too high, there will be a significant loss of manganese. Cobalt is very valuable, so it is better to reduce the precipitation efficiency of cobalt. In order to improve the efficiency of manganese precipitation without losing too much cobalt, the $\mathrm{pH}$ value should ideally be 2 . As shown in Figure 10(b) through the XRD analysis results of the manganese product obtained after the precipitation, the precipitate should be composed of manganese oxide.

\subsubsection{Results of Cobalt and Nickel Precipitation}

After the precipitation of manganese, cobalt and nickel were then co-precipitated with ammonium oxalate, for which the precipitation results are shown in Figure 11(a). This figure shows the effect of $\mathrm{pH}$ on the precipitation efficiency of cobalt and nickel at $50^{\circ} \mathrm{C}$ for one hour. It can be seen that optimum cobalt and nickel precipitation efficiency occurs at pH 2 without causing precipitation of lithium ions. At $\mathrm{pH} 2$, the precipitation efficiency of cobalt and nickel is as high as $99 \%$. However, the efficiency of the precipitation of lithium ions is only $1.5 \%$, so the best $\mathrm{pH}$ choice is $\mathrm{pH} 2$. The results of the XRD analysis of the cobalt and nickel products obtained after the precipitation are shown in Figure 11(b). It can be seen that the precipitates should be cobalt oxalate hydrate $\left(\mathrm{Co}\left(\mathrm{C}_{2} \mathrm{O}_{4}\right) \cdot 2 \mathrm{H}_{2} \mathrm{O}\right)$ and nickel oxalate hydrate $\left.\left(\mathrm{Ni}\left(\mathrm{C}_{2} \mathrm{O}_{4}\right) \cdot 2 \mathrm{H}_{2} \mathrm{O}\right) \cdot \cdot 2 \mathrm{H} 2 \mathrm{O}\right)$, and there is no obvious impurity phase, which indicates that the product is of high purity.

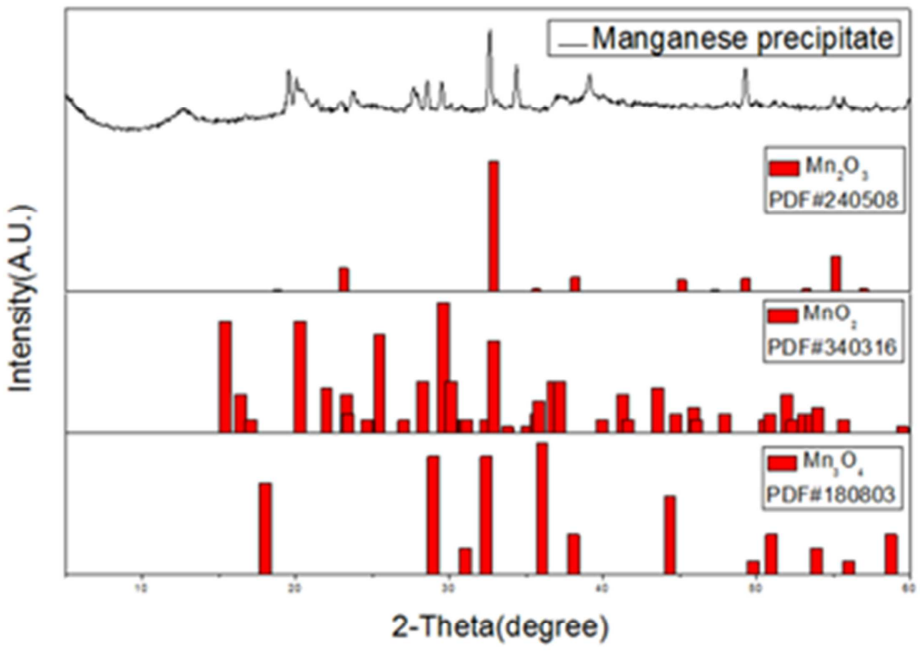

(b)

Figure 10. (a) Effect of pH on manganese precipitation (b) Crystal Phase Analysis of Manganese Precipitate. 


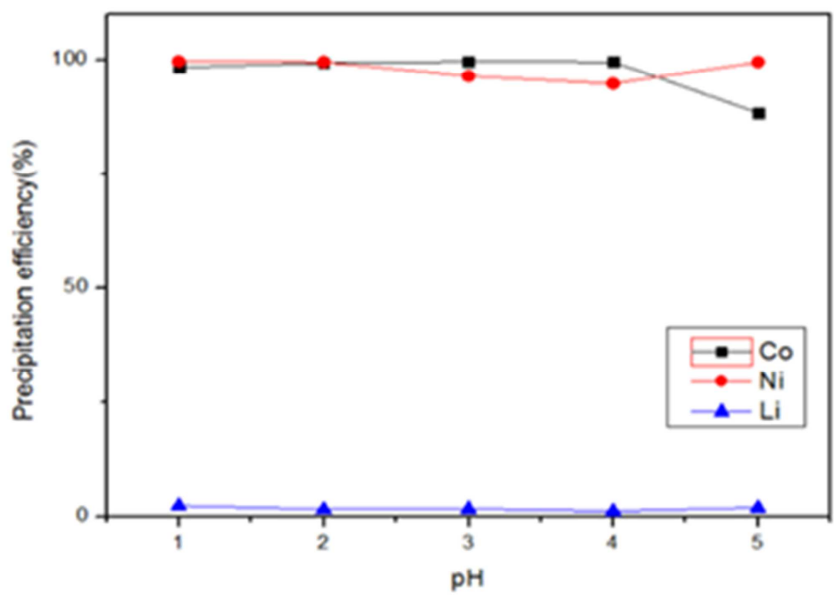

(a)

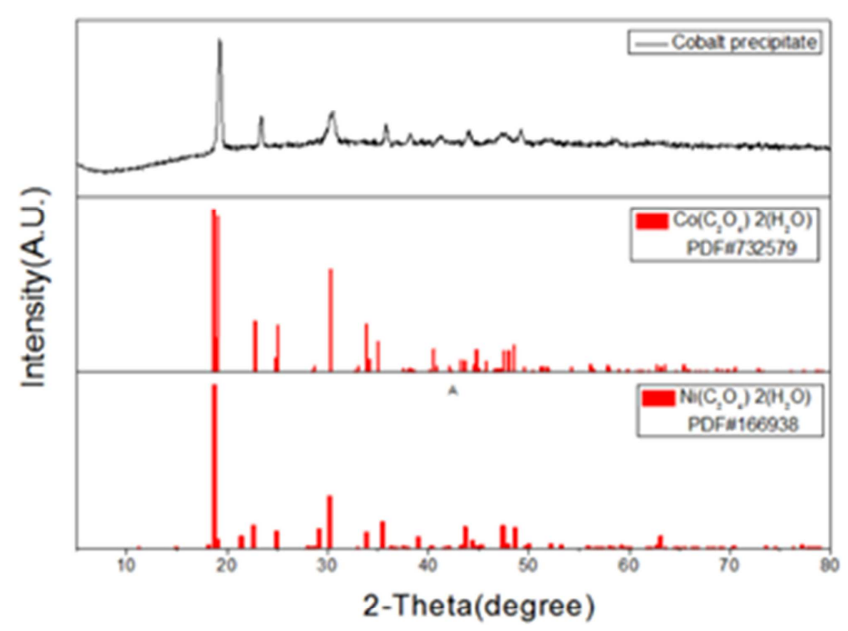

(b)

Figure 11. (a) Effect of pH on cobalt and nickel precipitation (b) Crystal Phase Analysis of Cobalt and Nickel Precipitate.

\subsubsection{Vacuum Concentration to Precipitate Lithium}

The impregnation liquid after the precipitation of cobalt and nickel contained a large amount of lithium ions, and there were almost no other ions, such as cobalt, nickel, manganese, etc., and the solution was clear and colorless.
The remaining impregnation liquid was placed in a rotary evaporator to do the vacuum concentration and heated to $90^{\circ} \mathrm{C}$. After about 30 minutes, a lithium precipitate was obtained. The finished product was identified as lithium chloride through XRD detection as shown in Figure 12.

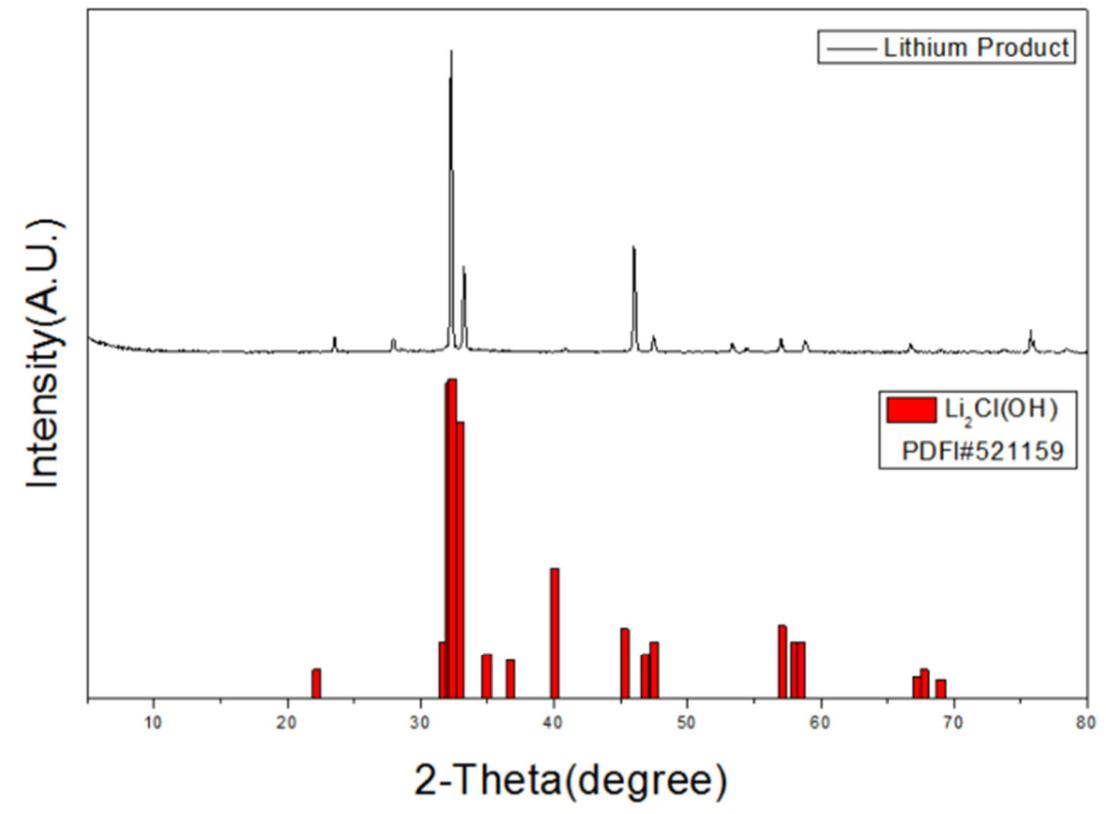

Figure 12. Crystal Phase Analysis of Lithium Precipitate.

\section{Conclusion}

This research method solves the thorny global problem of recycling lithium-ion batteries. Compared with the pyrometallurgical recycling technology, which is commonly used globally, this technology has a lower process cost, higher purity, and almost no pollution. We developed a complete lithium battery recovery solution from the physical pretreatment to the hydrometallurgy process. Waste lithium-ion batteries were recycled into high-purity valuable metals, which were reused by the lithium battery manufacturer to become a complete resource recycling system.

Based on the results obtained from this study, the following conclusions were drawn:

The best leaching conditions for sulfuric acid are: concentration, $2 \mathrm{M}$; solid-liquid ratio, $40 \mathrm{~g} / \mathrm{L}$; reaction time, $60 \mathrm{~min}$; temperature, $60^{\circ} \mathrm{C}$; a $5 \mathrm{vol} \%$ of hydrogen peroxide. The leaching efficiency for all of the metals of interest was over $95 \%$. The best leaching conditions for hydrochloric acid are: concentration, $4 \mathrm{M}$; solid-liquid ratio, $80 \mathrm{~g} / \mathrm{L}$; reaction time, $90 \mathrm{~min}$; temperature, $60^{\circ} \mathrm{C}$, and a $20 \mathrm{vol} \%$ of hydrogen 
peroxide. The leaching efficiency for all of the metals of interest was over $95 \%$. The best leaching conditions for citric acid are: concentration, $1 \mathrm{M}$; solid-liquid ratio, $40 \mathrm{~g} / \mathrm{L}$; reaction time, $120 \mathrm{~min}$; temperature $90^{\circ} \mathrm{C}$, and a $20 \mathrm{vol} \%$ of hydrogen peroxide, for which the leaching efficiency was Li:96\%, Co: 91\%, Ni: 98\%, Mn: 99\%. The manganese was precipitated by ammonium persulfate, where the best precipitation efficiency was obtained at $80^{\circ} \mathrm{C}, \mathrm{pH}=2$, with a reaction time $=$ one hour, and a molar ratio of $\left(\mathrm{S}_{2} \mathrm{O}_{8}{ }^{2-}\right):\left(\mathrm{Mn}^{2+}\right)$ $=2$. The precipitation efficiency reached $99 \%$, and the loss rate of cobalt was only $6 \%$. Cobalt and nickel were precipitated by ammonium oxalate. The best precipitation efficiency was obtained at $50^{\circ} \mathrm{C}$, with a $\mathrm{pH}=2$, a reaction time $=$ one hour, and a molar ratio of $\left(\mathrm{H}_{2} \mathrm{C}_{2} \mathrm{O}_{4}{ }^{2-}\right):\left(\mathrm{Co}^{2+}\right)=4$. The precipitation efficiency reached $99 \%$, and the loss rate of lithium was only $1.5 \%$. The remaining leaching liquid, mainly containing lithium ions, was concentrated through the use of reduced pressure evaporation to obtain lithium chloride. The concentration efficiency of lithium reached $99 \%$.

\section{Acknowledgements}

We wish to acknowledge the support of National Cheng Kung University's Department of Resources Engineering and the Ministry of Science and Technology, R. O. C.

\section{References}

[1] X. Chen, Y. Chen, T. Zhou, D. Liu, H. Hu, and S. Fan, Hydrometallurgical recovery of metal values from sulfuric acid leaching liquor of spent lithium-ion batteries. Elsevier, 2015, pp. 349-356.

[2] F. Pagnanelli, E. Moscardini, P. Altimari, T. A. Atia, and L. Toro, Leaching of electrodic powders from lithium ion batteries: Optimization of operating conditions and effect of physical pretreatment for waste fraction retrieval. Elsevier, 2017, pp. 706-715.

[3] Chiu, K. L.; Chen, W. S. Recovery and Separation of Valuable Metals from Cathode Materials of Spent Lithium-Ion Batteries (LIBs) by Ion Exchange. Sci. Adv. Mater. 2017, 9, 2155-2160.

[4] L. Chen, X. Tang, Y. Zhang, L. Li, Z. Zeng, and Y. Zhang, "Process for the recovery of cobalt oxalate from spent lithium-ion batteries," Hydrometallurgy, vol. 108, no. 1-2, pp. 80-86, 2011.

[5] J. - S. Sohn, D. - H. Yang, S. - M. Shin, and J.-G. Kang, "Recovery of Cobalt in Sulfuric Acid Leaching Solution Using Oxalic Acid," Geosystem Engineering, vol. 9, no. 3, pp. 81-86, 2006.

[6] S. - g. Zhu, W. - z. He, G. - m. Li, X. Zhou, X. -j. Zhang, and J. - w. Huang, "Recovery of Co and Li from spent lithium-ion batteries by combination method of acid leaching and chemical precipitation," Transactions of Nonferrous Metals Society of China, vol. 22, no. 9, pp. 2274-2281, 2012.

[7] T. Suzuki, T. Nakamura, Y. Inoue, M. Niinae, and J. Shibata, A hydrometallurgical process for the separation of aluminum, cobalt, copper and lithium in acidic sulfate media. Elsevier,
2012, pp. 396-401.

[8] L. Li, J. Ge, F. Wu, R. Chen, S. Chen, and B. Wu, Recovery of cobalt and lithium from spent lithium ion batteries using organic citric acid as leachant (no. 1-3). Elsevier, 2010, pp. 288-293.

[9] G. Granata, E. Moscardini, F. Pagnanelli, F. Trabucco, and L. Toro, "Product recovery from Li-ion battery wastes coming from an industrial pre-treatment plant: Lab scale tests and process simulations," Journal of Power Sources, vol. 206, pp. 393-401, 2012.

[10] J. -S. Sohn, S. -M. Shin, D.-H. Yang, J.-G. Kang, and K. Yoo, "Study of Physical Treatment of Spent Military Use Lithium Primary Batteries for Recycling," Geosystem Engineering, vol. 10, no. 2, pp. 27-30, 2007.

[11] L. Li, J. Ge, R. Chen, F. Wu, S. Chen, and X. Zhang, Environmental friendly leaching reagent for cobalt and lithium recovery from spent lithium-ion batteries (no. 12). Elsevier, 2010, pp. 2615-2621.

[12] L. Li, J. Ge, F. Wu, R. Chen, S. Chen, and B. Wu, Recovery of cobalt and lithium from spent lithium ion batteries using organic citric acid as leachant (no. 1-3). Elsevier, 2010, pp. 288-293.

[13] L. Li et al., Ascorbic-acid-assisted recovery of cobalt and lithium from spent Li-ion batteries. Elsevier, 2012, pp. 21-27.

[14] L. Li, R. Chen, F. Sun, F. Wu, and J. Liu, Preparation of LiCoO2 films from spent lithium-ion batteries by a combined recycling process (no. 3-4). Elsevier, 2011, pp. 220-225.

[15] B. Fan, X. Chen, T. Zhou, J. Zhang, and B. Xu, "A sustainable process for the recovery of valuable metals from spent lithium-ion batteries," Waste Manag Res, vol. 34, no. 5, pp. 474-81, May 2016.

[16] M. Contestabile, S. Panero, and B. Scrosati, A laboratory-scale lithium-ion battery recycling process (no. 1-2). Elsevier, 2001, pp. 65-69.

[17] J. Li, P. Shi, Z. Wang, Y. Chen, and C.-C. Chang, A combined recovery process of metals in spent lithium-ion batteries (no. 8). Elsevier, 2009, pp. 1132-1136.

[18] R.-C. Wang, Y.-C. Lin, and S.-H. Wu, A novel recovery process of metal values from the cathode active materials of the lithium-ion secondary batteries (no. 3-4). Elsevier, 2009, pp. 194-201 .

[19] J. Li et al., Study of extraction and purification of Ni, Co and Mn from spent battery material (no. 1-2). Elsevier, 2009, pp. $7-12$.

[20] J.-H. Li et al., Study of spent battery material leaching process (no. 3). Elsevier, 2009, pp. 751-755.

[21] J. Kang, G. Senanayake, J. Sohn, and S. M. Shin, Recovery of cobalt sulfate from spent lithium ion batteries by reductive leaching and solvent extraction with Cyanex 272 (no. 3-4). Elsevier, 2010, pp. 168-171.

[22] J. Nan, D. Han, and X. Zuo, Recovery of metal values from spent lithium-ion batteries with chemical deposition and solvent extraction. Elsevier, 2005, pp. 278-284.

[23] S. M. Shin, N. H. Kim, J. S. Sohn, D. H. Yang, and Y. H. Kim, Development of a metal recovery process from Li-ion battery wastes (no. 3-4). Elsevier, 2005, pp. 172-181. 
[24] G. Dorella and M. B. Mansur, A study of the separation of cobalt from spent Li-ion battery residues (no. 1). Elsevier, 2007, pp. 210-215.

[25] D. A. Ferreira, L. M. Z. Prados, D. Majuste, and M. B. Mansur, Hydrometallurgical separation of aluminium, cobalt, copper and lithium from spent Li-ion batteries (no. 1). Elsevier, 2009, pp. 238-246.

[26] J. Nan, D. Han, M. Yang, M. Cui, and X. Hou, Recovery of metal values from a mixture of spent lithium-ion batteries and nickel-metal hydride batteries (no. 1-2). Elsevier, 2006, pp. 75-80.

[27] C. K. Lee and K.-I. Rhee, Preparation of $\mathrm{LiCoO} 2$ from spent lithium-ion batteries (no. 1). Elsevier, 2002, pp. 17-21.

[28] L. Sun and K. Qiu, Vacuum pyrolysis and hydrometallurgical process for the recovery of valuable metals from spent lithium-ion batteries. Elsevier, 2011, pp. 378-384.

[29] J. Li, G. Wang, and Z. Xu, Generation and detection of metal ions and volatile organic compounds (VOCs) emissions from the pretreatment processes for recycling spent lithium-ion batteries, Waste Manag, vol. 52, pp. 221-7, Jun 2016.

[30] D. L. Wood, J. D. Quass, J. Li, S. Ahmed, D. Ventola, and C. Daniel, Technical and economic analysis of solvent-based lithium-ion electrode drying with water and NMP, Drying Technology, vol. 36, no. 2, pp. 234-244, 2017.
[31] He, L. P.; Sun, S. Y.; Song, X. F.; Yu, J. G. Leaching process for recovering valuable metals from the LiNi1/3Co1/3Mn1/3O2 cathode of lithium-ion batteries, Waste Manag. vol. 64, pp.171-181, 2017.

[32] Pant, D.; Dolker, T. Green and facile method for the recovery of spent Lithium Nickel Manganese Cobalt Oxide (NMC) based Lithium ion batteries, Waste Manag, vol. 60, pp.689695, 2017.

[33] Takacova, Z.; Havlik, T.; Kukurugya, F.; Orac, D. Cobalt and lithium recovery from active mass of spent Li-ion batteries: Theoretical and experimental approach. Hydrometallurgy, vol.163, pp.9-17, 2016.

[34] Zhang, X.; Xue, Q.; Li, L.; Fan, E.;Wu, F.; Chen, R. Sustainable Recycling and Regeneration of Cathode Scraps from Industrial Production of Lithium-Ion Batteries. ACS Sustain. Chem. Eng. vol.4, pp. 7041-7049, 2016.

[35] Diekmanna, J.; Hanisch, C.; Froböse, L.; Schälicke, G.; Loellhoeffel, T.; Fölster, A.-S.; Kwade, A. Ecological Recycling of Lithium-Ion Batteries from Electric Vehicles with Focus on Mechanical Processes.J. Electrochem. Soc. 164, A6184-A6191, 2017.

[36] Barik, S. P.; Prabaharan, G.; Kumar, B. An innovative approach to recover the metal values from spent lithium-ion batteries. Waste Manag, vol. 51, pp. 222-226, 2016. 